\title{
Associations of parental feeding styles with child snacking behaviour and weight in the context of general parenting
}

\author{
Gerda Rodenburg ${ }^{1,2, *}$, Stef PJ Kremers ${ }^{3}$, Anke Oenema ${ }^{3}$ and Dike van de Mheen ${ }^{1,2}$ \\ 'IVO Addiction Research Institute, Heemraadssingel 194, 3021 DM Rotterdam, The Netherlands: \\ ${ }^{2}$ Erasmus Medical Center, Rotterdam, The Netherlands: ${ }^{3}$ Department of Health Promotion, Maastricht University, \\ Maastricht, The Netherlands
}

Submitted 16 August 2012: Final revision received 28 January 2013: Accepted 12 February 2013: First published online 26 March 2013

\begin{abstract}
Objective: To examine cross-sectional and longitudinal (one-year follow-up) associations of parental feeding styles with child snacking behaviour and weight in the context of general parenting, taking into account the multidimensionality of the controlling feeding style.

Design: Linear regression analyses were performed. Parents completed a questionnaire to measure five feeding style dimensions (Instrumental Feeding, Emotional Feeding, Encouragement, Overt Control and Covert Control) and children's fruit, energy-dense snack and sugar-sweetened beverage (SSB) intakes. Children's height and weight were measured to calculate their BMI Z-scores. Moderation by parenting style was tested by adding interaction terms to the regression analyses.

Setting: Observational study in the Netherlands.

Subjects: Parent-child dyads ( $n$ 1275) participating in the INPACT (IVO Nutrition and Physical Activity Child cohorT) study; children were (on average) 9 years of age.

Results: Instrumental Feeding and Emotional Feeding were negatively related to child fruit intake one year later and positively to (changes in) child energy-dense snack intake. Encouragement was negatively related to child energy-dense snacking and SSB intake one year later. Overt Control was cross-sectionally and prospectively related to (changes in) child energy-dense snacking and SSB intake in a negative direction. Covert Control showed similar associations with child energy-dense snacking and SSB intake as Overt Control. Although Covert Control was also positively related to child fruit intake and (changes in) child BMI Z-score, bootstrapping analyses revealed only a differential effect of Overt Control and Covert Control on child BMI Z-score one year later, with Covert Control displaying a stronger, positive association. Moderation analyses showed that some significant associations between parental feeding styles and outcome measures were dependent on the degree of psychological control and behavioural control.

Conclusions: Instrumental Feeding and Emotional Feeding may have a detrimental impact on children's snacking behaviour, while Encouragement, Overt Control and Covert Control may lead to less energy-dense snacking and less SSB intake. Overt Control and Covert Control have differential effects on child BMI Z-score one year later, which supports the idea that they should be treated as separate constructs. Prospective studies with a longer follow-up may elucidate the causal pathways between the various feeding styles and children's snacking behaviour and weight, as well as the moderating influences of psychological and behavioural control.
\end{abstract}

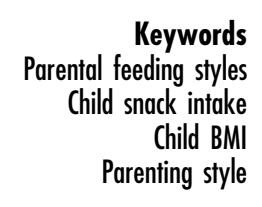

The prevalence of childhood overweight and obesity is increasing rapidly ${ }^{(1,2)}$. Consumption of energy-dense (snack) food and sugar-sweetened beverages (SSB) contributes to childhood overweight and obesity ${ }^{(3)}$. In children, energy-dense snacking and SSB intake have shown large increases over time ${ }^{(4)}$. In contrast, it is widely acknowledged that children consume less fruit than is recommended ${ }^{(5-9)}$, whereas fruit consumption is associated with a healthy body weight $^{(10-12)}$. Because snacking habits established in childhood often track through to adulthood ${ }^{(13,14)}$, unhealthy snacking (energy-dense snacks and SSB intake) should be discouraged and fruit snacking promoted at an early age. However, effective promotion of healthy eating requires understanding of the factors determining these behaviours. 
The home environment is a critical context for the development of children's snacking behaviour ${ }^{(15-17)}$. Parents play a key role in shaping the home environment, e.g. by using specific feeding styles. Parental feeding styles can be measured in various ways (e.g. references 18 and 19). Four commonly used aspects of parental feeding are Instrumental Feeding (i.e. using food to regulate a child's behaviour), Emotional Feeding (i.e. using food to temper a child's emotions), Encouragement to eat, and Control over eating ${ }^{(18)}$. Insight into such parental influences on children's snacking behaviour and weight may help the development of interventions targeted at parents ${ }^{(20-22)}$. However, data on parental feeding styles in relation to child snacking behaviour and BMI are inconsistent (see reference 23), e.g. there is evidence for positive associations, no associations and inverse associations of controlling feeding styles with child energy-dense snacking and weight. Explanations for such conflicting results include the study design (e.g. experimental $v$. observational studies and the cross-sectional nature of most studies) and the variety of parental feeding style measures used. The present study examines two ways to elucidate the relationship between parental feeding styles and child snack intake/weight, i.e. multidimensionality of parental feeding style constructs and higher-order moderation of general parenting.

The four feeding styles commonly distinguished are complex and multidimensional constructs (e.g. references 23 and 24). For example, Ogden et al. ${ }^{(24)}$ found evidence for expanding the existing conceptualisation of parental control into Overt Control and Covert Control. So far, parental control has mainly been operationalized in Overt Control, which is parental control over child food intake such that it can be detected by the child, e.g. by being firm about how much the child should eat. On the other hand, Covert Control is a way of parental control which is undetectable for the child, e.g. avoiding buying/having sweets/crisps in the home. In the study by Ogden et al., Overt Control was found to be unrelated to energy-dense snacking in children, while Covert Control was negatively associated with child snack intake ${ }^{(24)}$. This implies that adding the construct of Covert Control may elucidate the relationship between a controlling feeding style and child energy-dense snacking. However, studies are needed to replicate such findings, and to examine whether Overt Control and Covert Control also have differential effects on other snacking behaviours and weight.

The relationship between parental feeding styles and child snacking/weight has mainly been studied in an isolated perspective by not incorporating a broader parenting context. However, based on research and ecological systems theory ${ }^{(25)}$, there is a trend to integrate general parenting as a potential higher-order moderator in studies on parenting practices, e.g. to clarify mechanisms related to the impact of specific parenting on child consumption and weight (e.g. references 21 and 26-30). This implies that the impact of parental feeding styles on child snacking and weight may differ depending on the parents' general parenting style. A parenting style generates the environmental/ emotional context for child rearing, and can be operationalized into three dimensions: Involvement, Behavioural Control and Psychological Control ${ }^{(31)}$. Behavioural Control was found to have a positive impact on the relationship between parental modelling of fruit intake and child fruit intake (i.e. a more pronounced positive association between parental and child fruit intake among children of parents who consumed relatively large amounts of fruit) and Psychological Control a negative impact (i.e. a more pronounced positive association between parental and child fruit intake among children of parents who consumed relatively little fruit) ${ }^{(9)}$. This raises the question whether Psychological Control, seen as a risk factor for problem behaviour in general $^{(32,33)}$, also moderates the associations between parental feeding styles and child snacking/weight in an unfavourable way and whether Behavioural Control moderates the associations in a favourable way.

Associations between parental feeding styles and child snacking/weight are generally examined in cross-sectional studies, whereas longitudinal studies are sparse ${ }^{(21,34-36)}$. Therefore, in the present study we examined cross-sectional and longitudinal (one-year follow up) associations of parental feeding styles with child snacking (fruit intake, energy-dense snacking and SSB intake) and child weight in a community-based sample of (on average) 9-year-old children. We also examined whether adding Covert Control to the generally accepted concept of Overt Control may elucidate the relationship between a controlling feeding style and child snacking/weight. Finally, we examined whether the potential associations between parental feeding styles and child snacking/weight would be moderated by general parenting.

\section{Methods}

\section{Study design and procedure}

Data for the current study were retrieved from the longitudinal IVO Nutrition and Physical Activity Child cohorT (INPACT). INPACT was conducted according to the Declaration of Helsinki and all procedures were approved by the Medical Ethical Committee of the Erasmus MC (University Medical Center Rotterdam). Written informed consent was obtained from all participants.

INPACT is an observational study focusing on modifiable determinants of overweight in the home environment of primary-school children in the Netherlands, with emphasis on parental influences. The study included four assessments, in which qualified research assistants measured the children's height/weight at school and primary caregivers completed a questionnaire at home. Questionnaires recorded data on dietary intake of the child and potentially relevant home environmental factors, including parenting style dimensions, parental feeding style dimensions and 
sociodemographic variables. Assessments took place with a one-year time interval and started in the autumn of 2008 (baseline).

INPACT was conducted among primary-school children in southern Netherlands (Eindhoven area). All general primary schools in the area were invited to participate in the INPACT study. Of the 265 schools invited, ninety-one took part. The response rate from rural and urban schools was equal. The primary caregivers of third-grade students (aged 8 years) were invited to participate in the cohort study, together with their child. Of the 2948 parent-child dyads invited, $1839(62 \cdot 4 \%)$ gave informed consent to participate in the INPACT study for four years.

The present study was based on data from 2008 (baseline), 2009 and 2010. Sociodemographic variables and parenting style dimensions were measured at baseline, parental feeding style dimensions were measured in 2009 when the children were (on average) 9 years of age, while child fruit intake, snack intake, SSB intake and weight were measured in 2008, 2009 and 2010. Parentchild dyads who completed the parent questionnaires from baseline to 2010, and had valid child height/weight data in 2009 and 2010, were included in the present study, resulting in 1275 parent-child dyads (69.3\% of the original cohort). Logistic regression analyses on selective dropout from baseline to 2010 showed that non-Western and Western immigrant parent-child dyads dropped out more often. There was no selective dropout regarding child age/gender and parental education level.

\section{Measures}

Parental feeding styles

Parental feeding styles were parent-reported and measured using a validated Dutch translation ${ }^{\text {(23) }}$ of the Parental Feeding Style Questionnaire (PFSQ), designed and validated by Wardle and colleagues ${ }^{(18)}$. This twenty-seven-item measure assessed four feeding style dimensions: Instrumental Feeding, Emotional Feeding, Encouragement to eat, and Control over eating. The original measure, as well as the Dutch translation, have adequate to good internal consistency ${ }^{(18,23)}$. The control dimension of the PFSQ assessed Overt Control. Covert Control over eating was measured with three items, based on a five-item measure of Covert Control designed by Ogden et $a l .{ }^{(24)}$; this measure of Covert Control has adequate internal consistency (Cronbach's $\alpha$ of the original five-item measure $=0 \cdot 79$ ).

Missing data on the parental feeding style items (1.4\% at the highest for an Encouragement item) were imputed using the mean value of respondents without a missing value. Table 1 presents additional information on the five parental feeding style dimensions in our sample.

\section{Children's snacking behaviour}

Child fruit, energy-dense snack and SSB intakes were measured with a questionnaire based on validated $\mathrm{FFQ}^{(37,38)}$.

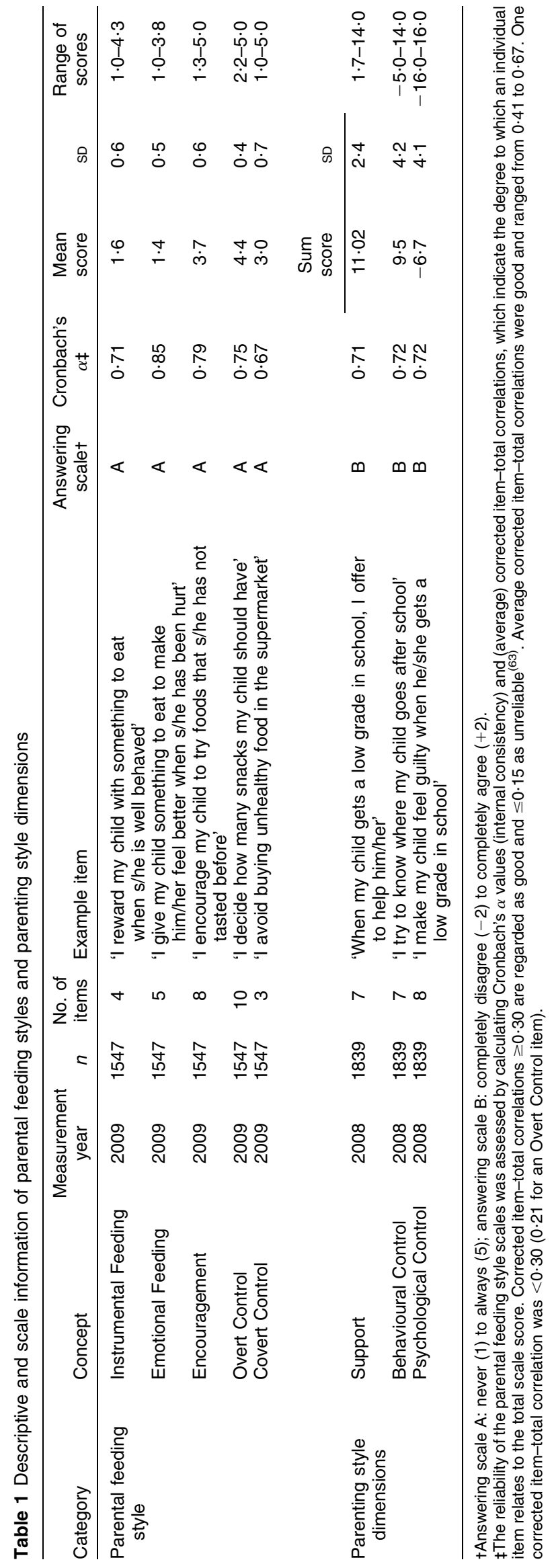


The primary caregivers reported how many days in a normal week their children consumed, in between meals: (i) fruit (fresh, bottled and/or canned; no juice); (ii) savoury snacks (e.g. potato crisps, peanuts and sausage rolls); (iii) sweet snacks (e.g. candies, chocolates and candy bars); (iv) cake or large biscuits; and (v) SSB. Answering categories ranged from 'none or less than 1 day a week' to '7 days a week'. They also reported the number of servings consumed by their children on such a day. For fruit, answering categories ranged from ' 0 pieces per day' to 'more than 3 pieces per day', by increments of half a piece of fruit. Reported consumption of more than 3 pieces/d ( $n$ 12) was recoded as 4 pieces/d. For savoury snacks, sweet snacks and cake or large biscuits, answering categories ranged from ' 0 ' to ' 10 servings a day'. For SSB, answering categories ranged from '0 glasses per day' to 'more than 5 glasses per day', by increments of half a glass. It was specified that one glass equals $200 \mathrm{ml}$; one can equals $330 \mathrm{ml}$ or 1.5 glasses; one bottle equals $500 \mathrm{ml}$ or $2 \cdot 5$ glasses. Reported consumption of more than 5 glasses/week ( $n$ 7) was recoded as 6 glasses/ week. Total child fruit and SSB intakes were expressed in servings per week and calculated by multiplying frequency and quantity. Total child energy-dense snack intake was also expressed in servings per week and calculated by multiplying frequencies of savoury snacks, sweet snacks and cakes with their corresponding quantities, and summing these scores. Missing values on these measures were not imputed due to the low number of missing values $(1 \cdot 0 \%$ at the highest, for child snacking).

\section{Children's weight}

Child BMI was based on the child's [weight (kg)]/[height $(\mathrm{m})]^{2}$ as measured by the qualified research assistants. Children were measured at school according to standard procedures in light clothing without shoes, to the nearest $0 \cdot 1 \mathrm{~kg}$ and $0 \cdot 1 \mathrm{~cm}$. BMI $Z$-scores were calculated ${ }^{(39)}$ based on age- and gender-specific values from the 1997 National Growth Study in the Netherlands ${ }^{(40)}$.

\section{Parenting style}

Parenting style was measured using the Dutch translation ${ }^{(41)}$ of an instrument based on earlier work by Steinberg et $a l^{(42,43)}$ and used in many studies worldwide ${ }^{(26,41,44,45)}$. With twenty-two items, the instrument assessed the parenting style dimensions of Support, Behavioural Control and Psychological Control (Table 1).

\section{Demographics and other potential confounders}

Measured potential confounders included child's gender, age and ethnic background, parental education level, parental fruit, energy-dense snack and SSB intakes, and parental BMI.

To assess the child's ethnic background, the primary caregiver reported the country of origin of both parents. According to standard procedures of Statistics Netherlands ${ }^{(46)}$, a child was classified as native Dutch if both parents were born in the Netherlands, as a Western immigrant if at least one parent was born outside the Netherlands but inside Europe, North America, Oceania, Indonesia or Japan, and as a non-Western immigrant if at least one parent was born in Turkey, Africa, Latin America or Asia. The primary caregiver also reported on his/her highest level of education. According to international classification systems $^{(47)}$, parental education level was defined as low (primary school and lower vocational/lower general secondary education), medium (intermediate vocational education, higher general secondary education and university preparatory), high (higher vocational education and university) or non-defined.

Parental fruit, energy-dense snack and SSB intakes were measured and calculated in the same way as child fruit, energy-dense snack and SSB intakes. To assess parental BMI, the primary caregiver reported his/her own height/ weight and that of his/her partner. He/she also reported whether he/she and the partner were the child's biological parents. Maternal and paternal BMI (for biological parents only) were calculated on the basis of their answers ( $n_{\text {maternal } \mathrm{BMI}}=1204,5 \cdot 6 \%$ missing; $n_{\text {paternal } \mathrm{BMI}}=1058$, $17 \cdot 0 \%$ missing). To maintain statistical power, missing values on maternal and paternal BMI were imputed using the group mean.

\section{Strategy for analyses}

To describe the study population, we computed means, standard deviations and/or proportions for the sociodemographic variables, parental feeding style dimensions, parenting style dimensions, child snacking behaviour and child BMI Z-scores.

To explore associations between the key study variables, Pearson's correlations were computed between parental feeding style dimensions (assessed in 2009), parenting style dimensions (assessed in 2008), child fruit intake in 2010, energy-dense snacking in 2010, SSB intake in 2010 and BMI $Z$-score in 2010. Next, separate linear regression analyses were performed to establish the longitudinal relationship between parental feeding style dimensions and child snacking/child BMI Z-score in 2010, adjusted for child age, gender, ethnic background and parental education level. In models with child snacking as dependent variable (e.g. child fruit consumption), we also controlled for child BMI in 2009 and parental snacking in 2010 (i.e. parental fruit consumption). In models with child BMI Z-score as dependent variable, we controlled for the sociodemographic variables and parental BMI in 2010. In these models, underweight children in 2009 (ninety-one of 1275 children) were excluded to prevent distortion of the results (for underweight children, an increase in BMI would be favourable whereas it would be unfavourable for normal weight, overweight and obese children). International cut-off scores were used to determine whether a child was underweight ${ }^{(39)}$.

To determine whether parental feeding style dimensions predicted changes in child snacking and BMI Z-score 
between 2009 and 2010, we repeated the linear regression analyses additionally adjusted for child snacking in 2009 and child BMI Z-score in 2009, respectively. Finally, to explore whether longitudinal associations between parental feeding style dimensions in 2009 and child snacking/ weight in 2010 were similar to cross-sectional associations, we performed cross-sectional linear regression analyses (parental feeding style dimensions and child snacking/ weight in 2009), applying the same adjustment procedure as in the longitudinal analyses.

In the final set of regression analyses we examined whether parenting style dimensions moderated significant longitudinal associations between parental feeding styles and (changes in) child snacking/child weight. Moderation was tested by adding interaction terms to the regression analyses. If interaction terms were significant

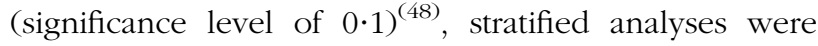
conducted by dichotomizing the sample on the relevant parenting dimension (median split).

All analyses were conducted using the statistical software package IBM SPSS Statistics version 19·0.

\section{Results}

In 2008, at baseline ( $n$ 1839), $7 \%$ of the children were underweight, $79 \%$ had normal weight and 14\% were overweight (of whom 3\% were obese). The age of the children was 8 years $(77 \%)$ or 9 years $(20 \%$; range 7-10 years, mean $8 \cdot 2(\mathrm{SD} 0 \cdot 5)$ years). Boys $(50 \cdot 5 \%)$ and girls $(49 \cdot 5 \%)$ were represented in almost equal numbers. Of all children, $17 \%$ were from a non-Dutch ethnic background (with one or both parents born abroad), of whom 9\% were from non-Western countries and $8 \%$ were from Western countries. Of all primary caregivers, 21\% had finished education at a low level, $45 \%$ at a medium level, $32 \%$ at a high level and $2 \%$ at a non-specified level (see Measures section for classification system used). Of the primary caregivers, $1 \%$ were underweight, $66 \%$ had a normal weight and 33\% were overweight (of whom 9\% were obese).

Parental feeding style and parenting style dimensions are described in Table 1. Parental feeding styles were measured in 2009, when the children were (on average) 9 years of age. Children had an average weekly fruit consumption of $7 \cdot 3$ (SD 4.2) pieces in 2009 and 6.9 (SD $4 \cdot 3$ ) pieces in 2010, an average weekly energy-dense snack intake of $9 \cdot 8(\mathrm{SD} 5 \cdot 8)$ pieces in 2009 and $9 \cdot 9(\mathrm{SD} 6 \cdot 1)$ pieces in 2010, an average weekly SSB intake of $9 \cdot 2$ (SD 8.2) glasses in 2009 and 8.9 (SD 8.2) glasses in 2010, and an average BMI $Z$-score of $0 \cdot 2$ (SD 0.9) in both 2009 and 2010 when underweight children were excluded.

Pearson's correlations between the key study variables are reported in Table 2 . It showed, among others, a positive correlation between Overt Control and Covert Control $(r=0 \cdot 09, P<0 \cdot 01)$, a negative association between child energy-dense snacking and child BMI Z-score in 2010 $(r=-0 \cdot 10, P<0 \cdot 001)$ and a negative association between child SSB intake and child BMI $Z$-score in $2010(r=-0 \cdot 06$, $P<0 \cdot 05)$. Results of the regression analyses with child snacking/child BMI Z-score in 2010 as the dependent variable (Table 3 , column ' $\beta_{2010}$ ') showed negative associations of Instrumental Feeding and Emotional Feeding with child fruit intake and positive associations with child energy-dense snack intake. Encouragement was negatively associated with child energy-dense snack and SSB intakes; Overt Control was also negatively associated with child energy-dense snack and SSB intakes; while Covert Control was positively associated with child fruit intake, negatively associated with child energy-dense snack and SSB intakes, and positively associated with child BMI Z-score. Effect sizes of the cross-sectional associations between parental feeding styles with child snacking/child BMI Z-score (Table 3, column ' $\beta_{2009}$ ') were generally similar to those for 2010 , but fewer of the cross-sectional associations reached statistical significance.

Results of regression analyses with child snacking/child BMI Z-score in 2010 as the dependent variable in which

Table 2 Pearson's correlations of key study variables ( $n$ 1275)

\begin{tabular}{|c|c|c|c|c|c|c|c|c|c|c|c|c|}
\hline & $n$ & 1 & 2 & 3 & 4 & 5 & 6 & 7 & 8 & 9 & 10 & 11 \\
\hline \multicolumn{13}{|c|}{ PFSQ constructs (assessed in 2009) } \\
\hline 1. Instrumental Feeding & 1275 & & & & & & & & & & & \\
\hline 2. Emotional Feeding & 1275 & $0.64^{* * *}$ & & & & & & & & & & \\
\hline 3. Encouragement & 1275 & 0.04 & -0.03 & & & & & & & & & \\
\hline 4. Overt Control & 1275 & $-0 \cdot 26^{\star \star *}$ & $-0 \cdot 39^{\star * *}$ & $0 \cdot 28^{* * *}$ & & & & & & & & \\
\hline 5. Covert Control & 1275 & $0 \cdot 11^{\star * *}$ & 0.01 & $0 \cdot 24^{\star \star *}$ & $0 \cdot 09^{* *}$ & & & & & & & \\
\hline \multicolumn{13}{|c|}{ Parenting style dimensions (assessed in 2008) } \\
\hline 6. Support & 1274 & $-0 \cdot 11^{\star \star *}$ & $-0 \cdot 10^{\star * *}$ & $0 \cdot 17^{* * *}$ & $0 \cdot 14^{\star \star \star}$ & -0.01 & & & & & & \\
\hline 7. Behavioural Control & 1274 & -0.04 & -0.03 & 0.05 & 0.05 & 0.02 & $0 \cdot 33^{\star \star \star}$ & & & & & \\
\hline 8. Psychological Control & 1274 & $0 \cdot 28^{\star * \star}$ & $0 \cdot 25^{\star * *}$ & $-0 \cdot 16^{\star * *}$ & $-0 \cdot 17^{\star * \star}$ & 0.00 & $-0 \cdot 14^{\star * *}$ & $0 \cdot 01$ & & & & \\
\hline \multicolumn{13}{|l|}{ Dependent variables in 2010} \\
\hline 9. Child fruit intake & 1272 & $-0 \cdot 06^{\star}$ & -0.03 & $0 \cdot 07^{\star}$ & -0.02 & $0 \cdot 15^{\star \star *}$ & 0.04 & $0 \cdot 08^{* *}$ & -0.03 & & & \\
\hline 10. Child energy-dense snacking & 1265 & $0 \cdot 11^{* * *}$ & $0 \cdot 14^{\star * *}$ & $-0 \cdot 11^{\star * *}$ & $-0 \cdot 16^{\star \star \star}$ & $-0 \cdot 17^{\star \star *}$ & -0.02 & 0.02 & 0.02 & 0.01 & & \\
\hline 11. Child SSB intake & 1267 & -0.01 & -0.01 & $-0 \cdot 06^{\star}$ & $-0.07^{\star}$ & $-0 \cdot 14^{\star \star *}$ & -0.03 & $-0.06^{*}$ & -0.02 & -0.05 & $0 \cdot 21^{\star \star *}$ & \\
\hline 12. Child BMI Z-scoret & 1184 & 0.06 & 0.03 & -0.04 & -0.02 & $0 \cdot 13^{\star * *}$ & -0.02 & -0.04 & $0 \cdot 10^{\star \star *}$ & 0.01 & $-0 \cdot 10^{* * *}$ & $-0.06^{\star}$ \\
\hline
\end{tabular}

PFSQ, Parental Feeding Style Questionnaire; SSB, sugar-sweetened beverage.

Correlation is significant at the: ${ }^{\star} 0.05$ level (two-tailed), ${ }^{\star \star} 0.01$ level (two-tailed), ${ }^{\star \star *} 0.001$ level (two-tailed).

tUnderweight children excluded. 
we additionally adjusted for child snacking/child BMI $Z$-score in 2009 (Table 3, column ' $\beta_{2010-2009}$ '), showed that Instrumental Feeding predicted a small decrease in child fruit consumption between 2009 and 2010 $(\beta=-0 \cdot 05, P<0 \cdot 05)$, a small increase in energy-dense snacking $(\beta=0 \cdot 08, P<0 \cdot 01)$ and a minimal increase in child BMI $Z$-score $(\beta=0 \cdot 02, P<0 \cdot 05)$. Emotional Feeding predicted a small increase in child energy-dense snacking $(\beta=0.07, \quad P<0.01)$, while Encouragement predicted a small decrease in child energy-dense snacking between 2009 and $2010(\beta=-0 \cdot 07, P<0 \cdot 01)$. Both Overt Control and Covert Control predicted small decreases in child energy-dense snack and SSB intakes (Overt Control: $\beta_{\text {snacking }}=-0.07, \quad P<0.01$ and $\beta_{\mathrm{SSB}}$ intake $=-0.07, \quad P<0.05 ; \quad$ Covert Control: $\beta_{\text {snacking }}=$ $-0 \cdot 06, P<0.01$ and $\beta_{\mathrm{SSB}}$ intake $=-0.08, P<0 \cdot 01$ ), while Covert Control also predicted a minimal increase in child BMI $Z$-score between 2009 and $2010(\beta=0 \cdot 02, P<0 \cdot 05)$.

Based on the results of the regression analyses, secondary analyses were performed to test the potential differential effect of Overt Control and Covert Control on child snacking behaviour and weight. In bootstrapping analyses, by constructing 1000 replicas of the observed data set, it was tested whether $\beta_{\text {Covert }}$ Control was significantly different from $\beta_{\text {Overt Control }}(P<0 \cdot 05)$. Bootstrapping analyses revealed that Overt Control and Covert Control had differential effects on child BMI Z-score in 2010, with Covert Control displaying a stronger, positive association. In addition, a trend $(0 \cdot 05<P<0 \cdot 1)$ was found for child BMI $Z$-score in 2009 and for changes in fruit intake between 2009 and 2010, with Covert Control displaying a positive change in fruit intake (Table 3).

Moderation analyses on significant longitudinal associations between parental feeding styles and (changes in) child snacking/child weight and subsequent stratified analyses revealed that the negative association between Instrumental Feeding and child fruit consumption was present only if primary caregivers scored relatively high on Behavioural Control, while the negative association between Overt Control and child SSB intake was present only when primary caregivers scored relatively low on Behavioural Control (Table 4). In addition, the positive association between Emotional Feeding and child energy-dense snack intake was present only in children of parents who conducted high levels of Psychological Control, while the negative association between Covert Control and child energy-dense snacking was present only in children of parents who conducted low levels of Psychological Control (Table 4). The parenting style dimension of Support did not moderate any of the significant longitudinal associations between parental feeding styles and child snacking/weight.

\section{Discussion}

Our study is one of the few to take into account the multidimensionality of parental feeding constructs, 
Table 4 Associations of parental feeding styles with child snacking, stratified by psychological control and behavioural control

\begin{tabular}{|c|c|c|}
\hline & & $\beta$ \\
\hline Child fruit intake $(n$ 1246) $\dagger$ & Behavioural Control & \\
\hline Instrumental Feeding $\ddagger$ & $\begin{array}{l}\text { Low } \\
\text { High }\end{array}$ & $\begin{array}{l}-0.05 \\
-0 \cdot 11^{\star *}\end{array}$ \\
\hline Child energy-dense snacking ( $n$ 1232)† & Psychological Control & \\
\hline Emotional Feeding $\$$ & $\begin{array}{l}\text { Low } \\
\text { High }\end{array}$ & $\begin{array}{l}0 \cdot 06 \\
0 \cdot 15^{\star *}\end{array}$ \\
\hline Covert Control\| & $\begin{array}{l}\text { Low } \\
\text { High }\end{array}$ & $\begin{array}{l}-0 \cdot 14^{\star \star *} \\
-0 \cdot 01\end{array}$ \\
\hline $\begin{array}{l}\text { Child SSB intake ( } n \text { 1241)† } \\
\text { Overt Control }\end{array}$ & $\begin{array}{l}\text { Behavioural Control } \\
\text { Low } \\
\text { High }\end{array}$ & $\begin{array}{l}-0.11^{* *} \\
-0.05\end{array}$ \\
\hline
\end{tabular}

SSB, sugar-sweetened beverage; $\beta$, standardized regression coefficient

Moderation was tested on significant longitudinal associations between parental feeding style subscales and (changes in) child intake/child BMI Z-score in 2010 (Table 3, column ' $\beta_{2010}$ ' and column ' $\beta_{2010-2009}$ '). Stratified analyses were only conducted for significant interaction terms. Stratified analyses were conducted by dividing the sample on the relevant parenting dimension in two (median split) and three groups, but stratification into two groups proved to be sufficient.

Correlation is significant at the: ${ }^{\star \star} 0.01$ level (two-sided), ${ }^{\star \star *} 0.001$ level (two-sided).

$+n$ deviates from sample sizes in Table 2 because of missing values on control variables.

$\ddagger P_{\text {interaction term }}=0.063$.

$\S P_{\text {interaction term }}=0.077$

$\| P_{\text {interaction term }}<0.001$.

- $P_{\text {interaction term }}=0.074$.

i.e. parental control over eating. Unlike previous findings ${ }^{(24)}$, in the present study Overt Control and Covert Control had no differential effect on (changes in) child energy-dense snack intake, as both were negatively related to child snack intake. However, they were differentially related to child BMI Z-score, while a trend was observed for changes in child fruit intake between 2009 and 2010. These new findings support the conclusion of Ogden et al. ${ }^{(24)}$ that Overt Control and Covert Control are separate constructs. In our study, Covert Control was positively related to child BMI Z-score, both cross-sectionally and prospectively, but the effect size of the predicted change in BMI $Z$-scores during one year was almost zero. This suggests that Covert Control might be an effective parental strategy in response to child weight problems. This latter idea is not new ${ }^{(24)}$ and is in line with data showing that parents modify their feeding practices (i.e. pressure to eat, restriction and monitoring) in response to the child's (perceived) weight, dietary behaviours and/or eating style ${ }^{(36,49-51)}$. In addition to the supportive effect of Overt Control and Covert Control on decreasing snack (and SSB) intake, Covert Control was also supportive in increasing child fruit intake. This suggests that parents who exert higher levels of Covert Control might replace the home availability of unhealthy snacks by home availability of fruit, which is positively related to fruit intake $e^{(15,20,22,52)}$.

Consistent with previous findings ${ }^{(23)}$, Encouragement was negatively related to child energy-dense snack intake, indicating that parental encouragement might be influenced by health beliefs: parents encourage their children's interest in and curiosity for a variety of healthy foods, resulting in the consumption of less unhealthy foods ${ }^{(23,49)}$.

Although Covert Control may be responsive to child weight, Instrumental Feeding and Emotional Feeding are less likely to be so because these styles are used for non-nutritive purposes. In previous studies, a positive association was found between Instrumental/Emotional Feeding and child energy-dense snack intake, indicating that parental use of energy-dense snacks as rewards may increase a child's preference for the 'rewarding' food ${ }^{(53,54)}$, which is expected to promote overeating of these products in children ${ }^{(23)}$. Our longitudinal findings on Instrumental Feeding (and to a lesser extent on Emotional Feeding) support this by assuming that these feeding styles might have a detrimental effect on child fruit intake, energydense snack intake and weight in the long run.

Prospective studies with a longer follow-up, in which all measures are assessed at baseline and follow-up, are needed to elucidate the causal pathways between various parental feeding styles and children's snacking behaviour and weight. To our knowledge, Webber et $a l^{(36)}$ were the first to study bidirectional longitudinal associations between a range of parental feeding styles and child adiposity, and concluded that monitoring and pressure to eat were responsive to the child's weight status. A next step is to test whether these responsive feeding styles lead to desired changes in child weight.

An increasing number of studies on parenting practices and child weight/intake include general parenting as a potential higher-order moderator ${ }^{(9,30,55,56)}$, thus incorporating a broader, non-food specific parenting context. To our knowledge, ours is the first study to relate parental feeding styles to child snacking and weight and include general parenting as a higher-order moderator, implying that the impact of parental feeding styles on child snacking and weight may differ depending on the parent's general parenting style. It is shown that some significant associations between parental feeding styles and outcome measures depend on the degree of Psychological Control 
and Behavioural Control. As hypothesized, a high level of Psychological Control was unfavourable for child snacking; this voided the negative association between Covert Control and child energy-dense snacking, and presented a positive association between Emotional Feeding and child energy-dense snacking. These findings demonstrate that it is not advisable for parents to use this method of control $^{(9,32,33)}$. Unexpectedly, our results indicate that low (instead of high) levels of Behavioural Control void the unfavourable negative association between Instrumental Feeding and child fruit intake, and increase the favourable negative association between Overt Control and child SSB intake. However, because of the large number of interaction terms tested, our moderation results should be interpreted with caution and more studies are needed before firm conclusions can be drawn.

Although our study has the strength of combining parental feeding styles, snack intake, weight and parenting style in one study, which is exceptional in this field of research $^{(21)}$, some limitations should be mentioned. First, we measured snack intake based on FFQ which may evoke social desirability bias and lead to overestimation of fruit consumption and underestimation of energy-dense snack and SSB intakes in parents and children ${ }^{(57,58)}$, especially in overweight subjects (e.g. references 59 and 60). Selective misreporting may explain the unexpected, negative correlations between energy-dense snacking and SSB intake on the one hand and child BMI Z-score on the other. However, there is evidence that selective misreporting in overweight children does not occur when parents report their child's food intake ${ }^{(61)}$, which is the case in our study. Reversed causality might be an alternative explanation for the negative correlations, implying that parents of children with a normal weight do not react on their child's energy-dense snacking and SSB intake (i.e. they do not get a signal that the amounts of energy-dense snacking are unhealthy), while parents of overweight children do.

Second, although parent-reported child snack intake may not lead to selective misreporting, parents might underestimate actual snacking intake of their children, as they are exposed to school food environments that parents may not be fully aware of. Because Dutch primary-school children bring their own snacks and food to school, underestimating of snacking intake had probably no (large) effect on our results. A third limitation is that our prospective study had a short follow-up of one year and did not measure parental feedings styles at both time points. Because of that, the benefits of a longitudinal approach could not be fully exploited. Fourth, we used an adapted version of Ogden's Covert Control scale. We combined two original items ('avoiding buying biscuits and cakes' and 'avoiding buying sweets and crisps') into one item on avoiding buying unhealthy foods. Moreover, we skipped one item on 'avoiding going to cafés or restaurants with your children which sell unhealthy food'.
A reduction in scale items from five to three might explain a lower Cronbach's $\alpha$ value of the adapted scale $(0 \cdot 67)$ compared with the original one $(0 \cdot 79)^{(62)}$. However, the internal consistency of the adapted scale was still acceptable $(0 \cdot 67)^{(62,63)}$ and our scale showed similar associations with child energy-dense snack intake as the original Covert Control scale. Fifth, parents reported on their general parenting style and feeding style, while there is evidence that child-reported parenting measures are more strongly related to child weight-related outcomes $^{(56,64,65)}$. However, child reports demand high literary skills of children, which cannot be expected from (on average) 9-year-old children. Finally, dropout analyses showed selective dropout on ethnicity; however, as this was not a main predictor and was controlled for, this probably had no effect on our results.

\section{Conclusion}

The current study indicates that both Instrumental Feeding and Emotional Feeding may have a detrimental impact on children's snacking behaviour by decreasing fruit intake and increasing energy-dense snack intake. In contrast, Encouragement, Overt Control and Covert Control may lead to less energy-dense snacking and less SSB intake. Overt Control and Covert Control appeared to have a differential effect on child BMI Z-score, which supports the idea that Overt Control and Covert Control should be treated as separate constructs. Psychological Control by parents had a detrimental impact on child energy-dense snack intake, i.e. voiding the protective effect of Covert Control on child snacking, while strengthening the positive association between Emotional Feeding and child snacking. Finally, our results suggested that Covert Control may be responsive to child weight, while Instrumental Feeding may cause an increase in child weight. Prospective studies with a longer follow-up are needed to clarify the causal pathways between the various parental feeding styles and children's snacking behaviour and weight.

\section{Acknowledgements}

Sources of funding: Financial support for the INPACT study was provided by ZonMw, the Netherlands Organisation for Health Research and Development (grant ID no. 121010011). ZonMw had no influence on the data analyses, interpretation and presentation. Conflict of interest: None of the authors had a conflict of interest. Authors' contributions: The authors' responsibilities were as follows. G.R., A.O., S.P.J.K. and D.v.d.M. designed the study. G.R. and D.v.d.M. conducted the study. G.R. performed the statistical analyses. All authors were involved in writing the manuscript and had final approval of the submitted version. Acknowledgements: The authors thank Ester Sleddens for providing them with the validated 
Dutch version of the PFSQ. The authors are very grateful to the schools, teachers, children and parents who participated in the INPACT study and to the research assistants who assisted in conducting the INPACT study.

\section{References}

1. Wang $\mathrm{Y}$ \& Lobstein $\mathrm{T}$ (2006) Worldwide trends in childhood overweight and obesity. Int J Pediatr Obes 1, $11-25$.

2. World Health Organization (2010) Childhood Overweight and Obesity on the Rise. Geneva: WHO.

3. Rennie KL, Johnson L \& Jebb SA (2005) Behavioural determinants of obesity. Best Pract Res Clin Endocrinol Metab 19, 343-358.

4. Piernas C \& Popkin BM (2010) Trends in snacking among US children. Health Aff (Millwood) 29, 398-404.

5. Currie C, Roberts C, Morgan A et al. (2004) Young People's Health in Context. Health Behaviour in School-aged Children (HBSC) Study: International Report from the 2001/2002 Survey. Copenhagen: WHO Regional Office for Europe.

6. Guenther P, Dodd K, Reedy J et al. (2006) Most Americans eat much less than recommended amounts of fruits and vegetables. J Am Diet Assoc 106, 1371-1379.

7. Huybrechts L, Matthys C, Vereecken CA et al. (2008) Food intakes by pre-school children in Flanders compared with recommendations. Int J Environ Res Public Health 5, $243-257$.

8. Jones LR, Steer CD, Rogers IS et al. (2010) Influences on child fruit and vegetable intake: sociodemographic, parental and child factors in a longitudinal cohort study. Public Health Nutr 13, 1122-1130.

9. Rodenburg G, Oenema A, Kremers SPJ et al. (2012) Parental and child fruit consumption in the context of general parenting, parental education and ethnic background. Appetite 58, 364-372.

10. Alinia S, Hels O \& Tetens I (2009) The potential association between fruit intake and body weight - a review. Obes Rev 10, 639-647.

11. World Health Organization (2002) The World Health Report. Reducing Risks, Promoting Healthy Life. Geneva: WHO.

12. World Health Organization (2003) Diet, Nutrition and the Prevention of Chronic Diseases. Joint WHO/FAO Expert Consultation. WHO Technical Report Series no. 916. Geneva: WHO.

13. Mikkilä V, Räsänen L, Raitakari OT et al. (2004) Longitudinal changes in diet from childhood into adulthood with respect to risk of cardiovascular diseases: the Cardiovascular Risk in Young Finns Study. Eur J Clin Nutr 58, 1038-1045.

14. Kelder SH, Perry CL, Klepp KI et al. (1994) Longitudinal tracking of adolescent smoking, physical activity, and food choice behaviors. Am J Public Health 84, 1121-1126.

15. Pinard CA, Yaroch AL, Hart MH et al. (2012) Measures of the home environment related to childhood obesity: a systematic review. Public Health Nutr 15, 97-109.

16. Kral TVE \& Rauh EM (2010) Eating behaviors of children in the context of their family environment. Physiol Behav 100, $567-573$.

17. Golan M \& Crow S (2004) Parents are key players in the prevention and treatment of weight-related problems. Nutr Rev 62, 39-50.

18. Wardle J, Sanderson S, Guthrie CA et al. (2002) Parental feeding style and the inter-generational transmission of obesity risk. Obes Res 10, 453-462.

19. Birch LL, Fisher JO, Grimm-Thomas K et al. (2001) Confirmatory factor analysis of the Child Feeding
Questionnaire: a measure of parental attitudes, beliefs and practices about child feeding and obesity proneness. Appetite 36, 201-210.

20. Pearson N, Biddle SJH \& Gorely T (2009) Family correlates of fruit and vegetable consumption in children and adolescents: a systematic review. Public Health Nutr 12, 267-283.

21. Ventura AK \& Birch LL (2008) Does parenting affect children's eating and weight status? Int J Behav Nutr Phys Act 5, 15.

22. Van der Horst K, Oenema A, Ferreira I et al. (2006) A systematic review of environmental correlates of obesityrelated dietary behaviors in youth. Health Educ Res 22, 203-226.

23. Sleddens EFCC, Kremers SPJ, De Vries NK et al. (2010) Relationship between parental feeding styles and eating behaviours of Dutch children aged 6-7. Appetite 54, 30-36.

24. Ogden J, Reynolds R \& Smith A (2006) Expanding the concept of parental control: a role for overt and covert control in children's snacking behaviour? Appetite 47, 100-106.

25. Bronfenbrenner U (1979) The Ecology of Human Development: Experiments by Nature and Design. Cambridge, MA: Harvard University Press.

26. Kremers SPJ, Brug J, de Vries H et al. (2003) Parenting style and adolescent fruit consumption. Appetite 41, 43-50.

27. Kremers SPJ (2010) Theory and practice in the study of influences on energy balance-related behaviors. Patient Educ Couns 79, 291-298.

28. Rhee K (2008) Childhood overweight and the relationship between parent behaviors, parenting style, and family functioning. Ann Am Acad Pol Soc Sci 615, 11-37.

29. Joyce JL \& Zimmer-Gembeck MJ (2009) Parent feeding restriction and child weight. The mediating role of child disinhibited eating and the moderating role of the parenting context. Appetite 52, 726-734.

30. Sleddens EFC, Gerards SMPL, Thijs C et al. (2011) General parenting, childhood overweight and obesity-inducing behaviors: a review. Int J Pediatr Obes 6, e12-e27.

31. Darling N \& Steinberg L (1993) Parenting style as context: an integrative model. Psychol Bull 113, 487-496.

32. Barber BK \& Harmon EL (2002) Violating the self: parental psychological control of children and adolescents. In Intrusive Parenting: How Psychological Control Affects Children and Adolescents, pp. 15-52 [BK Barber, editor]. Washington, DC: American Psychological Association.

33. Finkenauer C, Engels RCM \& Baumeister RF (2005) Parenting behaviour and adolescent behavioural and emotional problems: the role of self-control. Int J Behav Dev 29, 58-69.

34. Carnell S \& Wardle J (2007) Associations between multiple measures of parental feeding and children's adiposity in United Kingdom preschoolers. Obesity (Silver Spring) 15, 137-144.

35. Lehto R, Ray C \& Roos E (2011) Longitudinal associations between family characteristics and measures of childhood obesity. Int J Public Health 57, 495-503.

36. Webber L, Cooke LJ, Hill C et al. (2010) Child adiposity and maternal feeding practices: a longitudinal analysis. $\mathrm{Am} \mathrm{J}$ Clin Nutr 92, 1423-1428.

37. Bogers RP, Van Assema P, Kester AD et al. (2004) Reproducibility, validity, and responsiveness to change of a short questionnaire for measuring fruit and vegetable intake. Am J Epidemiol 159, 900-909.

38. Haraldsdottir J, Thorsdottir I, de Almeida MDV et al. (2005) Validity and reproducibility of a precoded questionnaire to assess fruit and vegetable intake in European 11- to 12-year-old schoolchildren. Ann Nutr Metab 49, 221-227.

39. Cole TJ, Bellizzi MC, Flegal KM et al. (2000) Establishing a standard definition for child overweight and obesity worldwide: international survey. BMJ 320, 1240-1246. 
40. Fredriks AM, Van Buuren S, Wit JM et al. (2000) Body index measurements in 1996-7 compared with 1980. Arch Dis Child 82, 107-112.

41. Beyers W \& Goossens L (1999) Emotional autonomy, psychosocial adjustment and parenting: Interactions, moderating and mediating effects. J Adolesc 22, 753-769.

42. Steinberg L, Elmen JD \& Mounts NS (1989) Authoritative parenting, psychosocial maturity, and academic success among adolescents. Child Dev 60, 1424-1436.

43. Lamborn SD, Mounts NS, Steinberg L et al. (1991) Patterns of competence and adjustment among adolescents from authoritative, authoritarian, indulgent, and neglectful families. Child Dev 62, 1049-1065.

44. Huver RME, Engels RCME, Vermulst AA et al. (2007) Is parenting style a context for smoking-specific parenting practices? Drug Alcohol Depend 89, 116-125.

45. Pearson N, Atkin AJ, Biddle SJ et al. (2010) Parenting styles, family structure and adolescent dietary behaviour. Public Health Nutr 13, 1245-1253.

46. Statistics Netherlands (2000) Standaarddefinitie allochtonen. In Hoe doet het CBS dat nou?, pp. 24-25. Voorburg: Statistics Netherlands.

47. Eurostat (2007) Task Force on Core Social Variables. Final Report. Luxembourg: European Communities.

48. Rosnow RL \& Rosenthal R (1989) Statistical procedures and the justification of knowledge in psychological science. Am Psychol 44, 1276-1284.

49. Webber L, Hill C, Cooke LJ et al. (2010) Associations between child weight and maternal feeding styles are mediated by maternal perceptions and concerns. Eur J Clin Nutr 64, 259-265.

50. Webber L, Cooke LJ, Hill C et al. (2010) Associations between children's appetitive traits and maternal feeding practices. J Am Diet Assoc 110, 1718-1722.

51. Gregory JE, Paxton SJ \& Brozovic AM (2010) Pressure to eat and restriction are associated with child eating behaviours and maternal concern about child weight, but not child body mass index, in 2- to 4-year-old children. Appetite $\mathbf{5 4}$, 550-556.

52. Rasmussen M, Krølner R, Klepp KI et al. (2006) Determinants of fruit and vegetable consumption among children and adolescents: a review of the literature. Part I: quantitative studies. Int J Behav Nutr Phys Act 3, 22.
53. Birch LL, Birch D, Marlin DW et al. (1982) Effects of instrumental consumption on children's food preference. Appetite 3, 125-134.

54. Newman J \& Taylor A (1992) Effect of a means-end contingency on young children's food preferences. $J$ Exp Child Psychol 53, 200-216.

55. van der Horst K, Kremers SPJ, Ferreira I et al. (2007) Perceived parenting style and practices and the consumption of sugar-sweetened beverages by adolescents. Health Educ Res 22, 295-304.

56. Taylor A, Wilson C, Slater A et al. (2011) Parent- and childreported parenting. Associations with child weight-related outcomes. Appetite 57, 700-706.

57. Baranowski T, Smith M, Baranowski J et al. (1997) Low validity of a seven-item fruit and vegetable food frequency questionnaire among third-grade students. J Am Diet Assoc 97, 66-68.

58. Van Assema P, Brug J, Ronda G et al. (2002) A short Dutch questionnaire to measure fruit and vegetable intake: relative validity among adults and adolescents. Nutr Health 16, 85-106.

59. Livingstone MBE, Robson PJ \& Wallace JMW (2007) Issues in dietary intake assessment of children and adolescents. Br J Nutr 92, Suppl. 2, S213-S222.

60. Livingstone MBE \& Robson PJ (2000) Measurement of dietary intake in children. Proc Nutr Soc 59, 279-293.

61. Hise ME, Sullivan DK, Jacobsen DJ et al. (2002) Validation of energy intake measurements determined from observerrecorded food records and recall methods compared with the doubly labeled water method in overweight and obese individuals. Am J Clin Nutr 75, 263-267.

62. Field A (2005) Discovering Statistics Using SPSS, 2nd ed. London: SAGE Publications Ltd.

63. Nunnally J (1978) Psychometric Theory, 2nd ed. New York: McGraw-Hill.

64. Barr-Anderson D (2010) Parental report vs. child perception of familial support: which is more associated with child physical activity and television use? J Phys Act Health 7, 364-368.

65. Haines J, Neumark-Sztainer D, Hannan P et al. (2008) Child versus parent report of parental influences on children's weight-related attitudes and behaviors. J Pediatr Psychol 33, 783-788. 